\title{
Examination of heat insulation features of thermal resistant paints with use of IR camera
}

\author{
by T. Kruczek*, I. Szczygieł*, G. Kruczek* and P. Kowalczyk*
}

\begin{abstract}
*Institute of Thermal Technology, Silesian University of Technology, 44-100 Gliwice, Poland, tadeusz.kruczek@polsl.pl

*Institute of Thermal Technology, Silesian University of Technology, 44-100 Gliwice, Poland, ireneusz.szczygiel@polsl.pl

*Institute of Thermal Technology, Silesian University of Technology, 44-100 Gliwice, Poland, PhD student, grzegorz.kruczek@polsl.pl

*Institute of Thermal Technology, Silesian University of Technology, 44-100 Gliwice, Poland, MSc student, p.kowalczyk900@gmail.com
\end{abstract}

\section{Abstract}

To reduce heat losses from buildings various methods are used. One of them is applying so called "thermal resistant paints". These paints can be put in principle on the inner but also on outer surfaces of building external walls. The aforementioned paints are put on a surface in the similar way as other paints in building construction technology and form a thin insulation layer. The acting of this paints consists in causing a noticeable temperature drop within this layer and simultaneously on the wall surface. This work presents the descriptions of the experimental rig, measurement procedures and selected measurement results.

\section{Introduction and aim of the work}

For the diminution of heat losses through external walls of buildings and other objects many various techniques, methods and materials can be applied [1, 2, 3]. One of them is the coating of wall surface with a thin layer of special paints containing unique ingredients. These paints can be used for covering the outer walls surface inside or outside buildings.

The aim of this work was the recognition of insulation properties of such paint layers and possibilities of potential expected effects evaluation.

For testing these paints it was necessary to prepare special samples. For preparation of these samples a typical gypsum plate, very often used in building construction technology, was applied. The thickness of this plate amounted to $12.5 \mathrm{~mm}$. The plate was cut to obtain the samples of size $200 \times 200 \mathrm{~mm}$. Afterwards, the pieces of the plate were covered with the tested paints. Several different samples are shown in Fig. 1. On the painted surfaces the special areas were formed which were useful for observation of considered thermal effects as well as for checking the thickness of the paint layer.
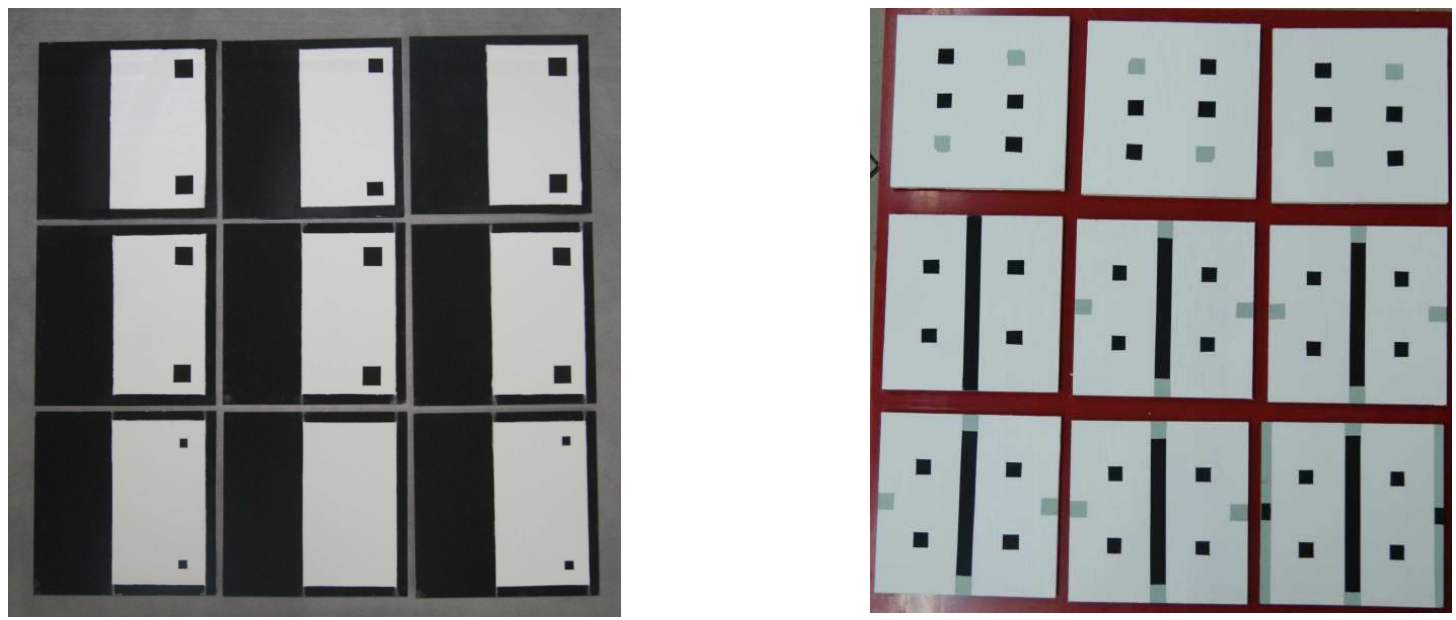

Fig. 1. The gypsum samples covered with the considered materials used in the experimental testing 


\subsection{1/qirt.2016.067}

\section{General description of the experimental rig and measurements}

The main element of the experimental unit was a measurement board 1 with the exact flat front surface, Fig. 2 . To ensure a uniform temperature field on the measurement surface the board was made of copper. The board was heated or cooled by a work agent flowing inside the copper tubes 2 welded to rear side of the mentioned board, Fig. 2 . The work agent at required temperature was prepared in a cryostat. Four pieces of such boards were put into measurement chamber of the laboratory unit, Fig. 3. During the experiments the tested samples 5 were fixed to measurement board, Fig. 3. For the measurement of temperature on the front side of the tested samples the infrared camera (IR camera) 8 was used, Fig. 3. In Fig. 4 is presented a general scheme of the experimental rig. It is known that infrared measurement results are sensitive to the thermal radiation of surrounding elements, therefore it is necessary to determine this effect $[4,5]$. For that reason the temperature of inner surfaces of the measurement chamber walls were measured by means of about 20 glued thermocouples 6 (Fig. 4) and recorded periodically by the computerized data acquisition system $[4,5]$. To avoid an uncontrolled flow of air through the measurement chamber, it had a relatively good level of air tightness. The air temperature inside the chamber was formed by additional independent cryostat 9 which supplied the work agent 11 to a heat exchangers 3 located inside the work chamber, Fig. 4.

During the experiments the temperature distributions on the front side of the tested samples were measured and recorded by means of infrared camera. The final results of such measurements are very sensitive to measurement errors [6,7]. The main task of the walls chamber was to create unambiguously defined surroundings of the tested surface [5]. The temperature of the air inside the measurement chamber was kept at the required level. This air temperature and the temperature of inner surfaces of the chamber walls were continuously measured and recorded (see thermocouples 5, 6, Fig. 4).
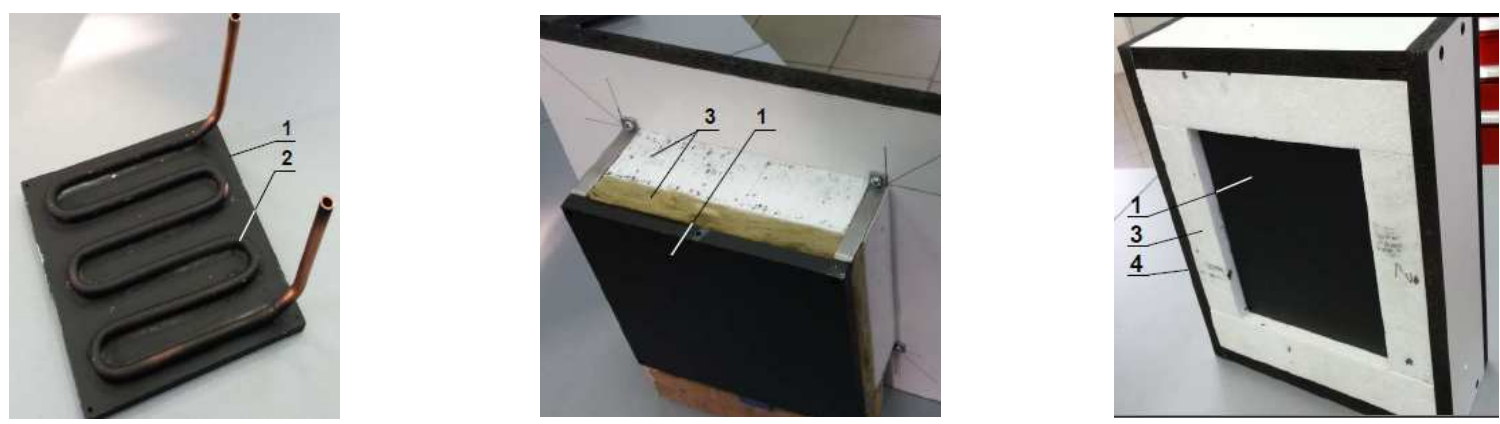

Fig. 2. Construction of main heating/cooling board; 1-copper board, 2-tortuous tube for cooling/heating agent, 3thermal insulation, 4-external casing
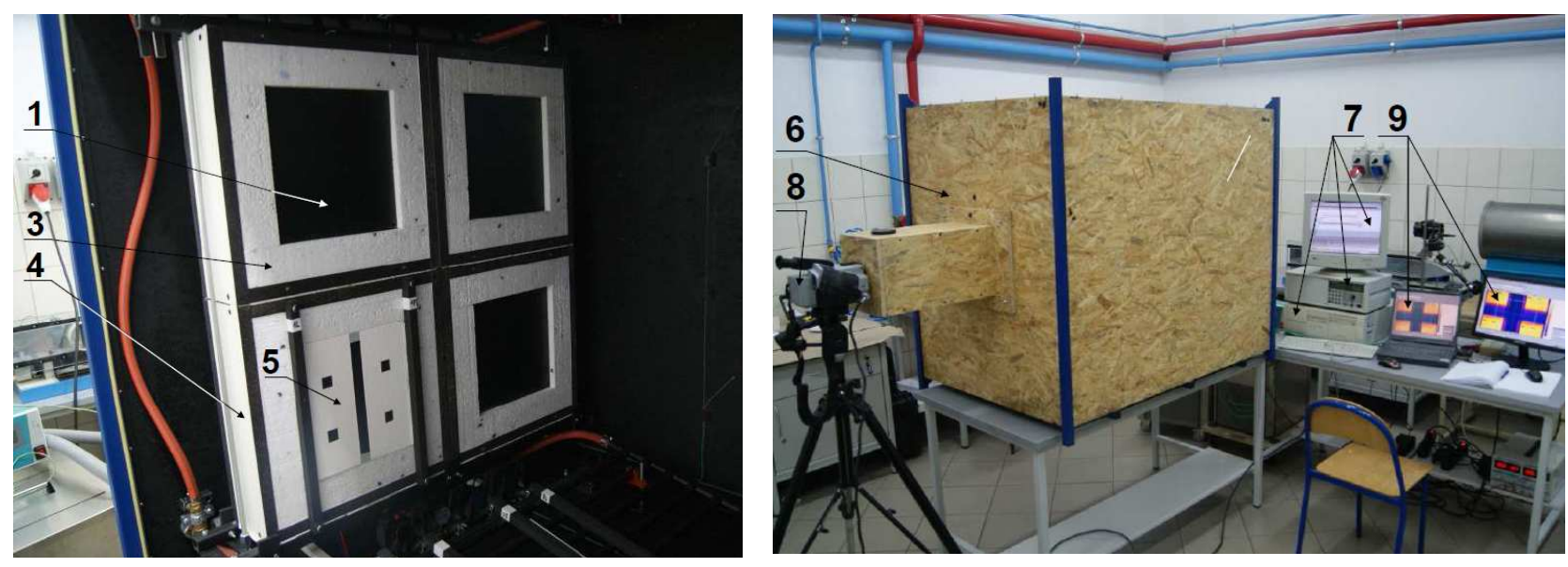

Fig. 3. Laboratory unit inside (on the left) and seen from outside (on the right), 1-copper board, 3-thermal insulation, 4external casing, 5-tested sample, 6-measurement chamber, 7-computer data acquisition system, 8-infrared camera, 9computer control system of infrared camera 


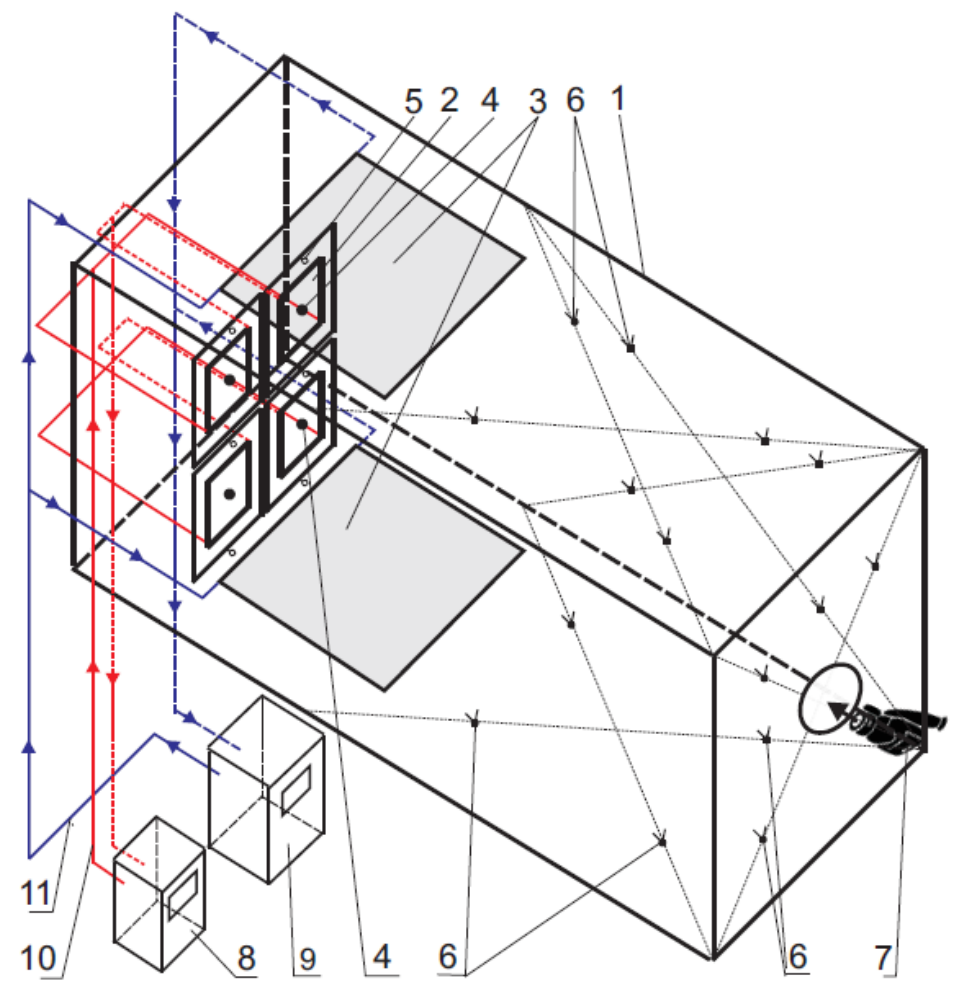

Fig. 4. Scheme of the laboratory unit, 1-work chamber, 2-copper board, 3-bottom and top air cooler/heater, 4thermocouples for measurement of the copper board temperature. 5-thermocouples for measurement of air temperature in the immediate vicinity of the tested samples, 6-thermocouples for temperature measurement of work chamber walls, 7-infrared camera, 8-cryostat for heating/cooling the copper boards and simultaneously tested samples, 9-cryostat for cooling/heating air inside the work chamber, 10-circulating agent in the heating/cooling system of copper boards, 11circulating agent in system of keeping air temperature at a required level

Generally, the measurement results were recorded by means of IR camera after reaching the conditions of steady state in heat transfer by the measurement system. In these conditions all temperature values were stable over time. During the experiments the following quantities were measured and recorded: IR camera thermograms, temperature in several points on inner surfaces of measurement chamber walls, the temperature of copper boards, general air temperature inside the abovementioned chamber and the temperature of air in the immediate vicinity of the examined surfaces of tested samples. Usually the thermograms were recorded ten times for each measurement. Next, the measurement results recorded by IR camera were exported by the camera software and read with three significant decimal digits. For further analysis the arithmetic mean calculated on the basis of the aforementioned ten recorded thermograms was used. The arithmetic mean of temperature was rounded to two significant decimal places.
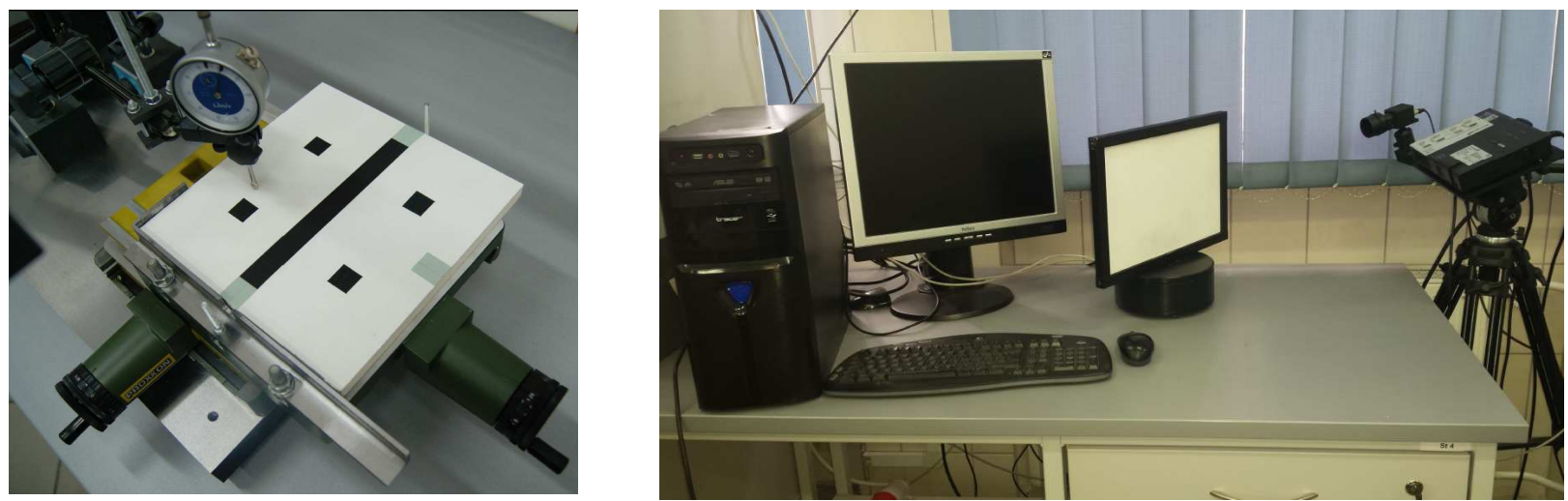

Fig. 5. Measuring equipment for measurement of the thickness of paint layers, dial thickness gauge (on the left) and $3 D$ scanner (on the right) 


\subsection{1/qirt.2016.067}

\section{Analysis of selected measurement results}

In the first step the samples denoted by $\mathrm{X} 1, \mathrm{X} 2, \mathrm{X} 7$ and $\mathrm{X} 8$ were tested. Figure 6 shows the examples of thermograms, which were made for a temperature of copper boards amounting to $45^{\circ} \mathrm{C}$ and $55^{\circ} \mathrm{C}$. The measur ement results were recorded after the stabilization of temperature distribution i.e. for the conditions of steady state in heat transfer.
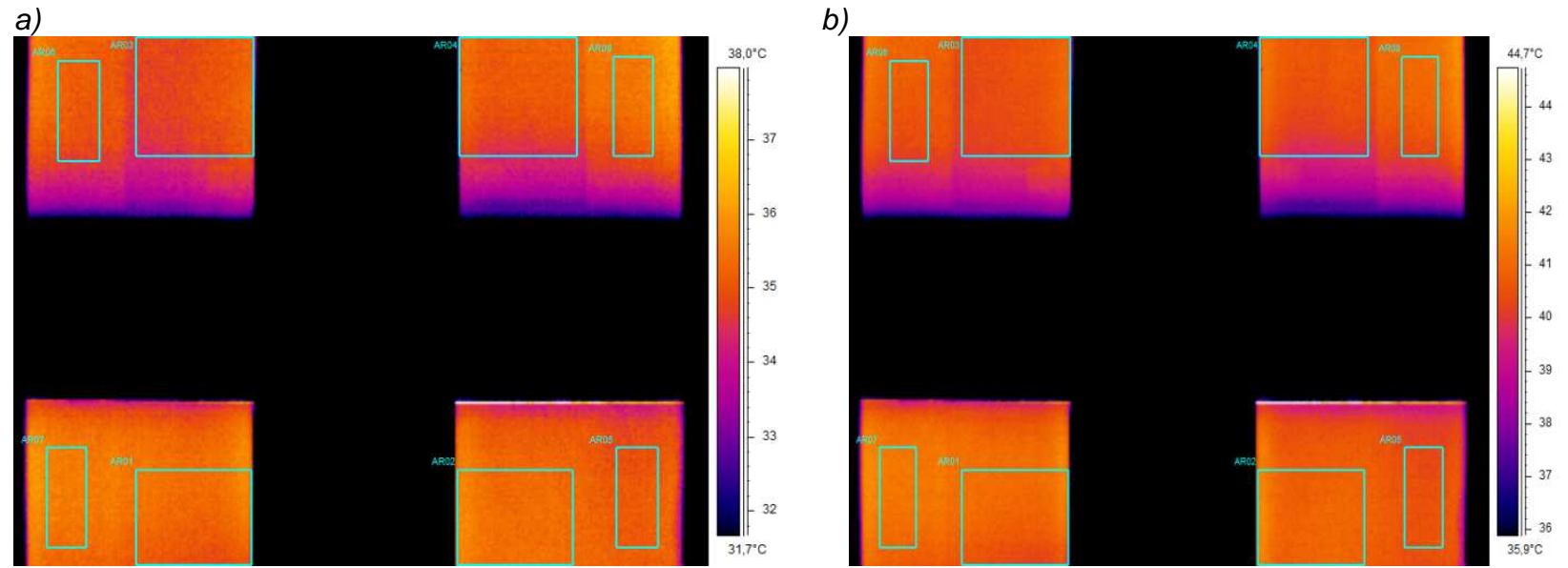

Fig. 6. Thermograms of temperature distribution for the temperature of copper boards: a) $45^{\circ} \mathrm{C}$ (on the left); b) $55^{\circ} \mathrm{C}$ (on the right)

In Fig. 6 on all thermograms eight rectangles with names: AR01, AR02, AR03, AR04, AR05, AR06, AR07 and AR08 were located. These surfaces show average temperature values of areas covered with "thermal resistant paints" (AR01, AR02, AR03, AR04) and the temperature of reference surfaces with measurement areas AR05, AR06, AR07, AR08. The surfaces AR01, AR02 have dimensions of $54 \times 43$ pixels and the surfaces AR05, AR07 of $19 \times 45$ pixels and they are located on samples X7 (lower left side) and X8 (lower right side). However, the areas AR03, AR04 have dimensions of $54 \times 54$ pixels and the fields AR06, AR08 of $19 \times 45$ pixels. They are located on samples X1 (top, on the left) and X2 (top, on the right). The surfaces AR01, AR02, AR03 and AR04 were used to measure the temperature of paint and the surfaces AR05, AR06, AR07 and AR08 were used for measuring the temperature of reference surfaces. The size of areas from AR01 to AR04 have been designated for the specific surfaces of plates, for which previously was measured the thickness of tested paint. The areas with size of $54 \times 43$ pixels cover field samples with size of $9 \times 7.2 \mathrm{~cm}$, however, dimensions of $54 \times 54$ pixels corresponds to the area size of $9 \times 9 \mathrm{~cm}$ on the tested sample. The size of other rectangles was determined randomly, because they were only the reference surfaces.

The aforementioned thermograms for samples $X 7, X 8$ were examined and a temperature drop was not observed on them. A noticeable temperature drop occurred on plates $\mathrm{X} 1$ and $\mathrm{X} 2$, where the temperature of copper boards was equal to $55^{\circ} \mathrm{C}$ and the difference between temperature of reference surfaces and temperature of painted surfaces amounts properly $0.09 \mathrm{~K}$ (sample X1) and $0.37 \mathrm{~K}$ (sample X2). The similar temperature difference was obtained for these plates, where the temperature of copper boards amounted to $45^{\circ} \mathrm{C}$. The temperature difference of plate $\mathrm{X} 1$ was approximately equal to zero (because only $0.02 \mathrm{~K}$ ), while the temperature difference for the plate $\mathrm{X} 2$ amounted to $0.37 \mathrm{~K}$. The temperature drop is closely connected with the paint thickness, which for the plate X1 amounts to $0.3 \mathrm{~mm}$, while for the sample X2 is equal to $0.29 \mathrm{~mm}$. Figures 7, 8 show the approximate appearance of paint surface and changes of layer thickness according to the size of considered area (Fig. 7) and according to the measurement path length inside this area (Fig. 8). For the plates $X 7$ and $X 8$ the similar figures were not drawn because the temperature drop was negligibly small. It was caused by a very small thickness of paint layers. In this case the thickness amounted to less than $0.2 \mathrm{~mm}$, approximately about $0.1 \mathrm{~mm}$.. 

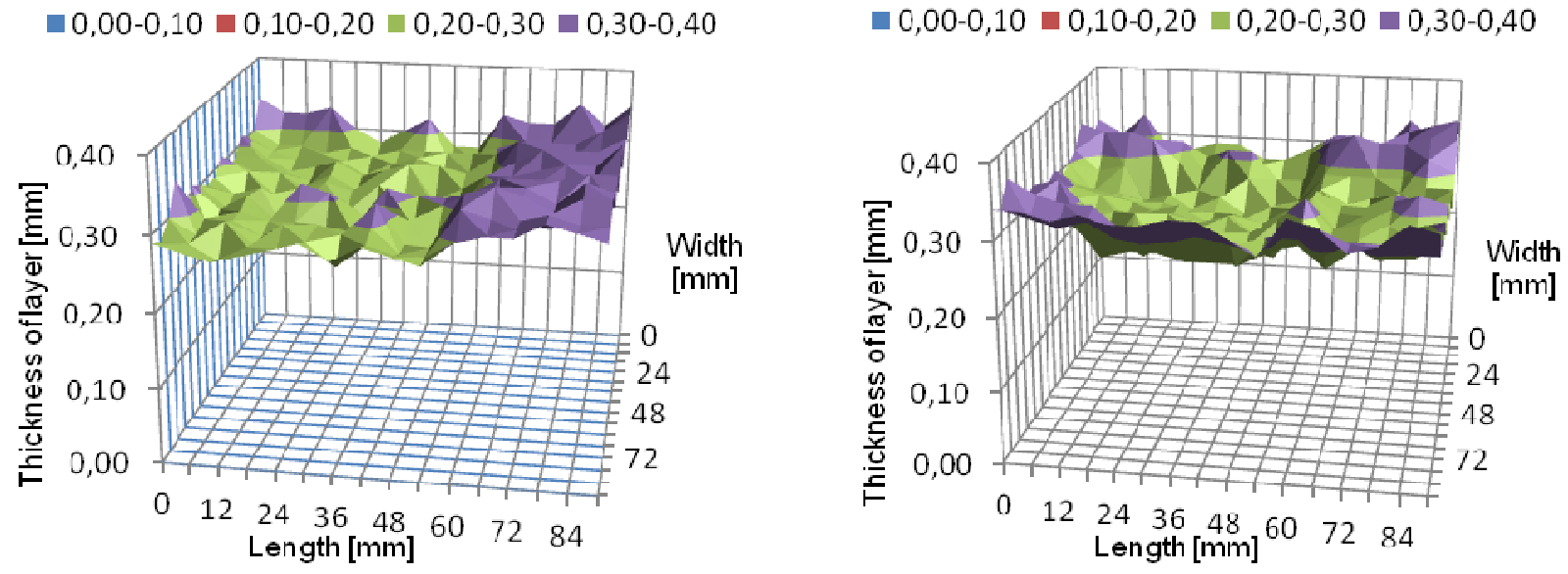

Fig. 7. Surface graphs of the layer thickness for the sample X1 (on the left) and X2 (on the right)
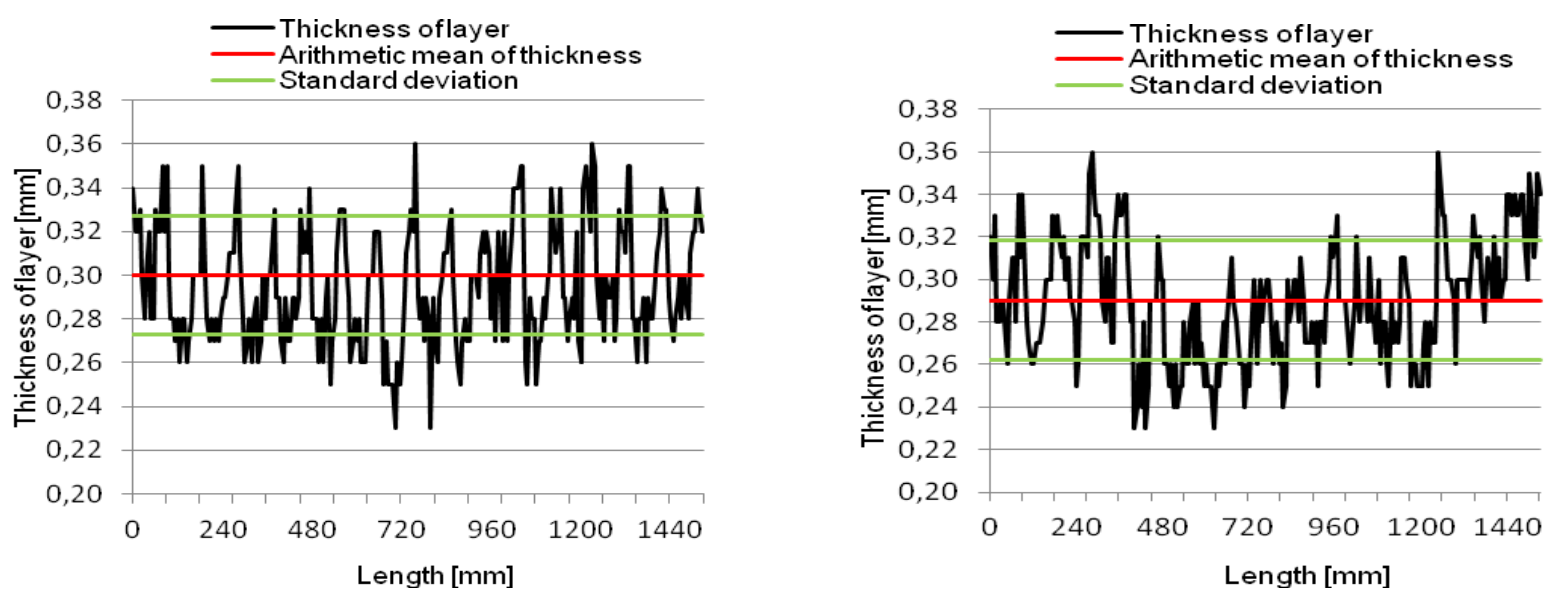

Fig. 8. Graphs of the thickness distribution of paint layer along the measurement path length for the sample X1 (on the left) and $X 2$ (on the right)

In the next step the samples denoted by $\mathrm{X} 3, \mathrm{X} 4, \mathrm{X} 5 \mathrm{a}$ and $\mathrm{X} 6$ were tested. Figure 9 shows the thermograms of these samples. The thermograms were made for a temperature of copper boards equaled to $45{ }^{\circ} \mathrm{C}$ and $55^{\circ} \mathrm{C}$. The final measurement results were recorded after reaching the conditions of steady state in heat transfer by the measurement system. In these conditions the temperature distribution values were stable over time.

In the similar way as previously the eight rectangular measurement areas $A 01 \div A 08$ have been created for the thermograms given in Fig. 9. The areas had the same sizes and realized the same functions as previously.

These examples of the thermograms show temperature drops on all samples with the examined "thermal resistant paints". The temperature drops are higher and clearer than for the previous samples. The temperature differences between reference surfaces and examined surfaces for the sample X3 (lower left side) are equal to $0.19 \mathrm{~K}$ and $0.48 \mathrm{~K}$ for the temperature of copper board amounting to $45^{\circ} \mathrm{C}$ and $55^{\circ} \mathrm{C}$, respectively. For the plate $\mathrm{X} 4$ (lower right side) this differences amount to $0.49 \mathrm{~K}$ and $0.68 \mathrm{~K}$, while the temperature drops on plates $\mathrm{X} 5$ (a) (top left side) and X6 (top right side) are equal to $0.07 \mathrm{~K}, 0.29 \mathrm{~K}$ and $0.48 \mathrm{~K}, 0.60 \mathrm{~K}$, respectively. The thicknesses of paint layers on the aforementioned plates are equal to $0.32 \mathrm{~mm}$ (plate X3), $0.28 \mathrm{~mm}$ (plate X4), $0.19 \mathrm{~mm}$ (plate X5a) and $0.40 \mathrm{~mm}$ (plate $\mathrm{X6}$ ). Figures 10, 11 show an approximate appearance of painted surfaces and the changes of layer thickness along the measurement path length. Bigger temperature drops at higher temperatures of copper boards and at thicker layers of paints were observed. The sample with the thickest layer has a significantly higher temperature drop than the sample which has the thinnest layer. 

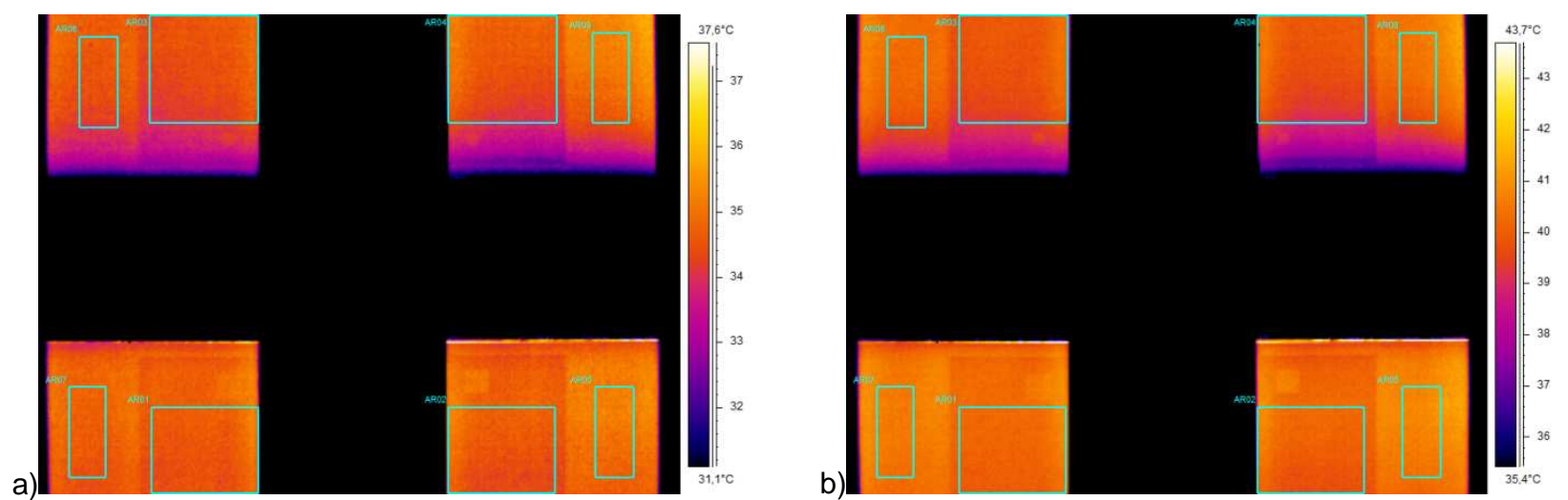

Fig. 9. Thermograms of temperature distributions for the specified temperature values of copper boards: a) $45^{\circ} \mathrm{C}$; b) $55^{\circ} \mathrm{C}$

a)

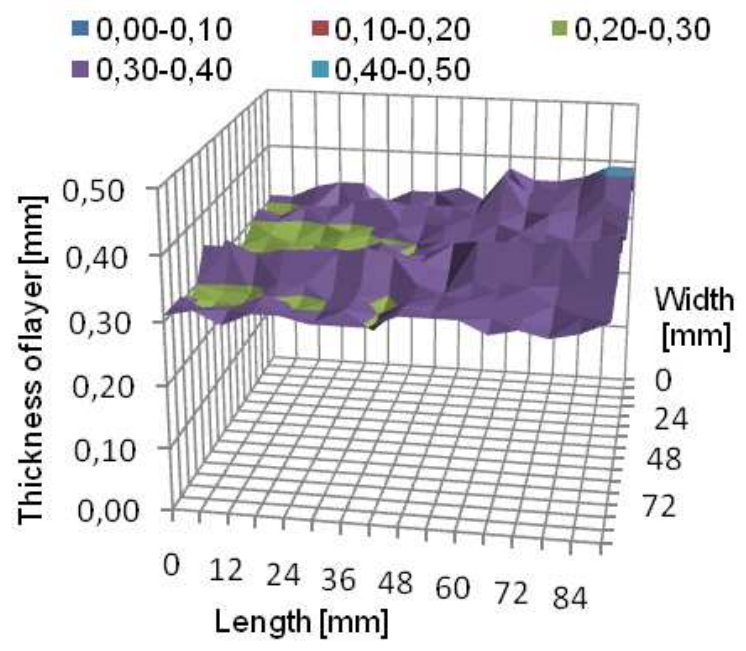

c)

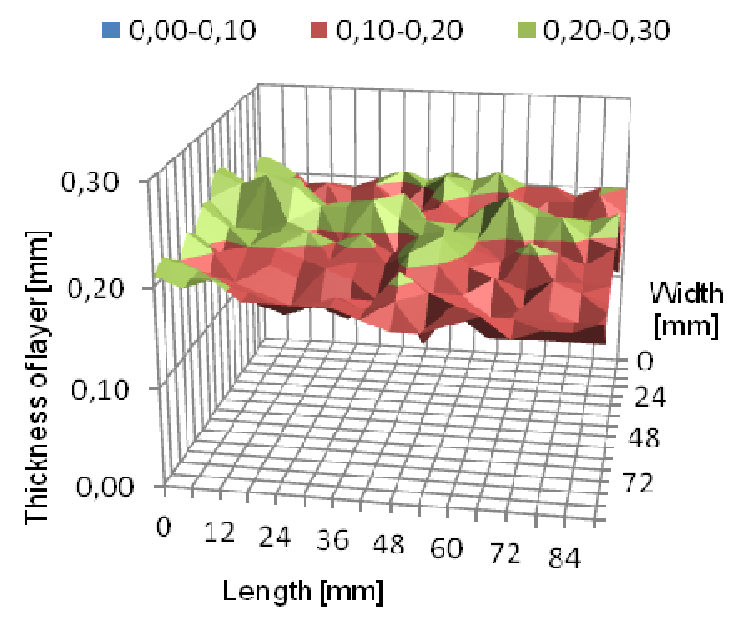

b)

$\square, 00-0,10 \square 0,10-0,20 \square 0,20-0,30 \square 0,30-0,40$

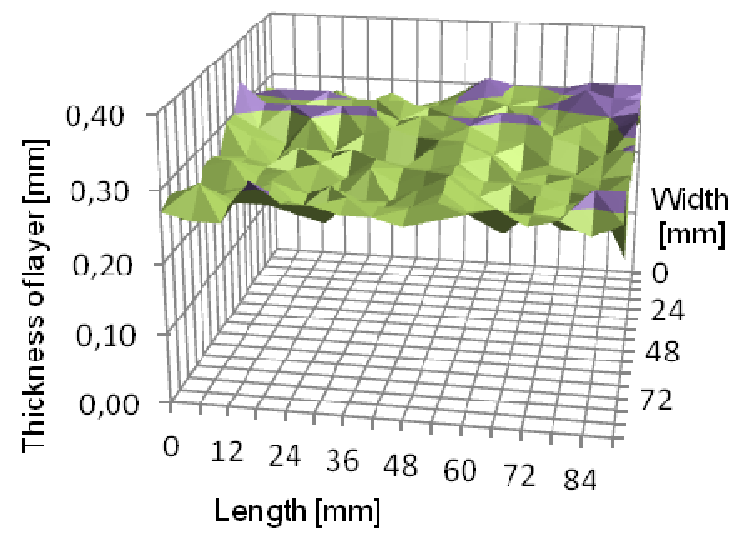

d)

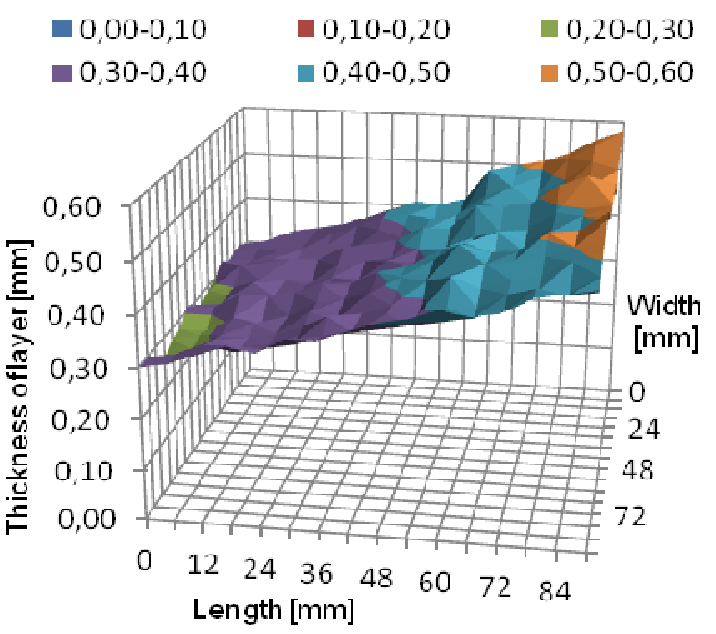

Fig. 10. Surface graphs of layer thickness for the samples: a) X3; b) X4; c) X5a; d) X6 
a)

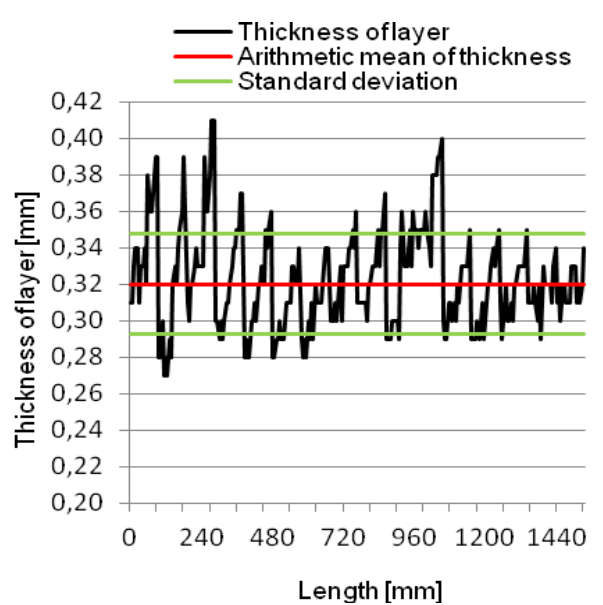

c)

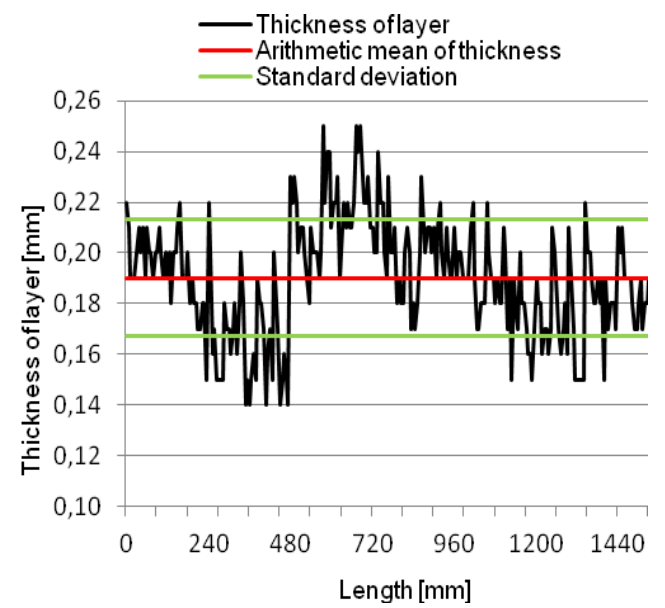

b)

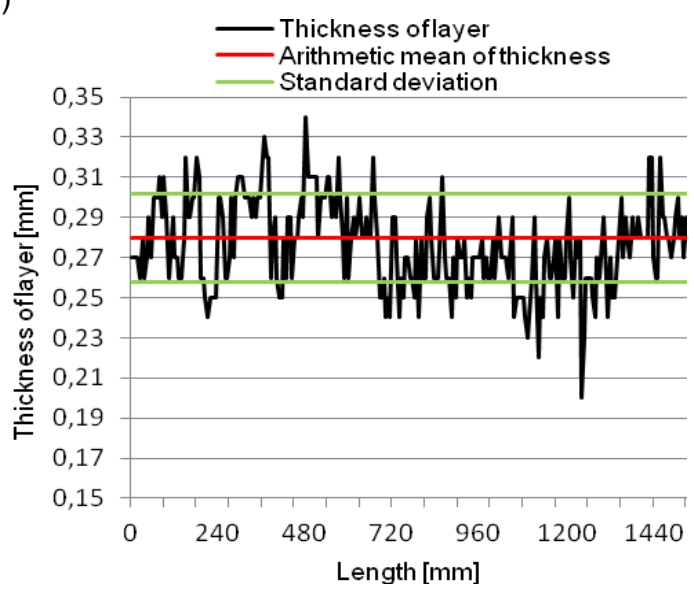

d)

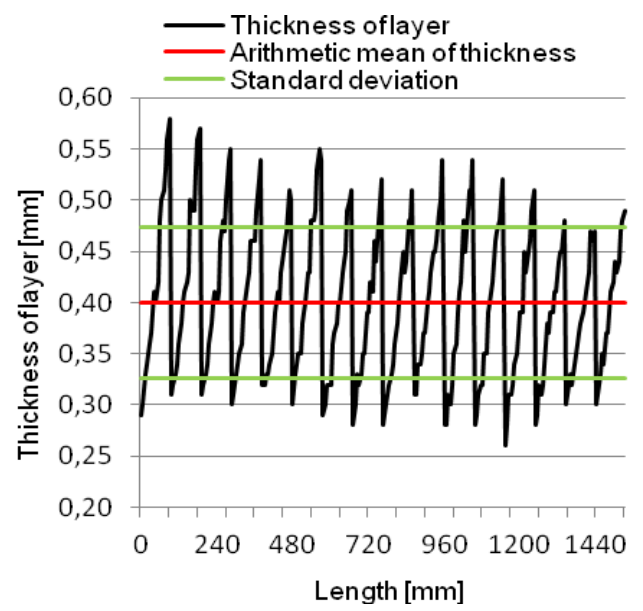

Fig. 11. Graphs of the thickness distribution of paint layer along the measurement path length for the specified samples: a) X3; b) X4; c) X5a; d) X6

Figure 12 shows the thermogram for different situation than the previous ones because it is made for a temperature of copper boards amounting to $10^{\circ} \mathrm{C}$. So, in this case the samples were cooled and the direction of heat flow was opposite to the previous one. The temperature of air within measurement chamber was equal to $29.2^{\circ} \mathrm{C}$. The photos were recorded during the steady state of thermal parameters within the measurement chamber. There are $\mathrm{X} 3, \mathrm{X} 4, \mathrm{X} 5 \mathrm{a}$ and $X 6$ samples in the same positions as previously. Eight rectangular measurement areas denoted by $A 01 \div A 08$ have been created in the similar way as in the previous description. These areas had the same sizes and realized the same functions as previously.

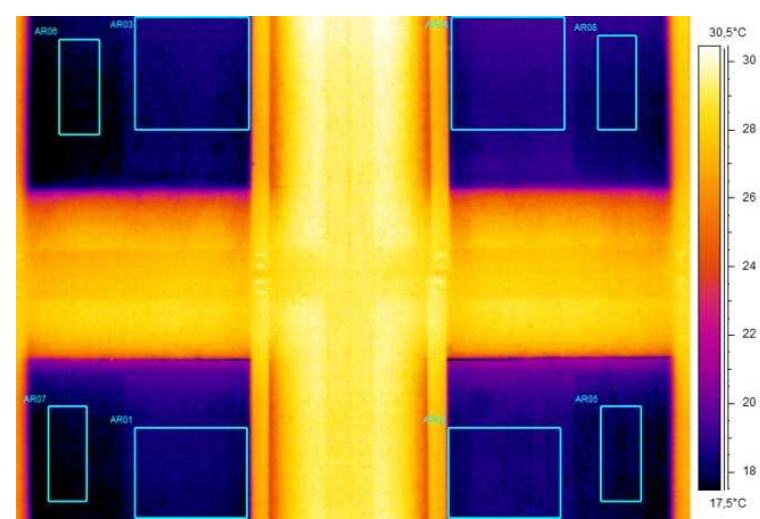

Fig. 12. Thermogram of the temperature distribution in the case of cooling the copper boards 


\subsection{1/qirt.2016.067}

As it was explained, in this case the direction of the heat flux flow was changed, because temperature of the copper boards was lower than air temperature. Heat flowed from surroundings through the examined samples to copper plates. In these conditions the rise of temperature of the examined surface by comparison with the temperature of reference surface was observed. The temperature difference between the examined surface of paint and reference surface for plate $\mathrm{X} 3$ amounted to $0.75 \mathrm{~K}$. This similar difference for plate $\mathrm{X} 4$ was equal to $0.71 \mathrm{~K}$, while the rise of temperatures on plates $\mathrm{X} 5 \mathrm{a}$ and $\mathrm{X} 6$ were equal to $0.92 \mathrm{~K}$ and $0.56 \mathrm{~K}$, respectively. The thickness of layers was not changed.

In the measurements of the thickness of paint coatings also a 3D scanner was used. In Fig. 13 an example of high resolution image of the tested coating surface obtained with the use of such scanner is presented.

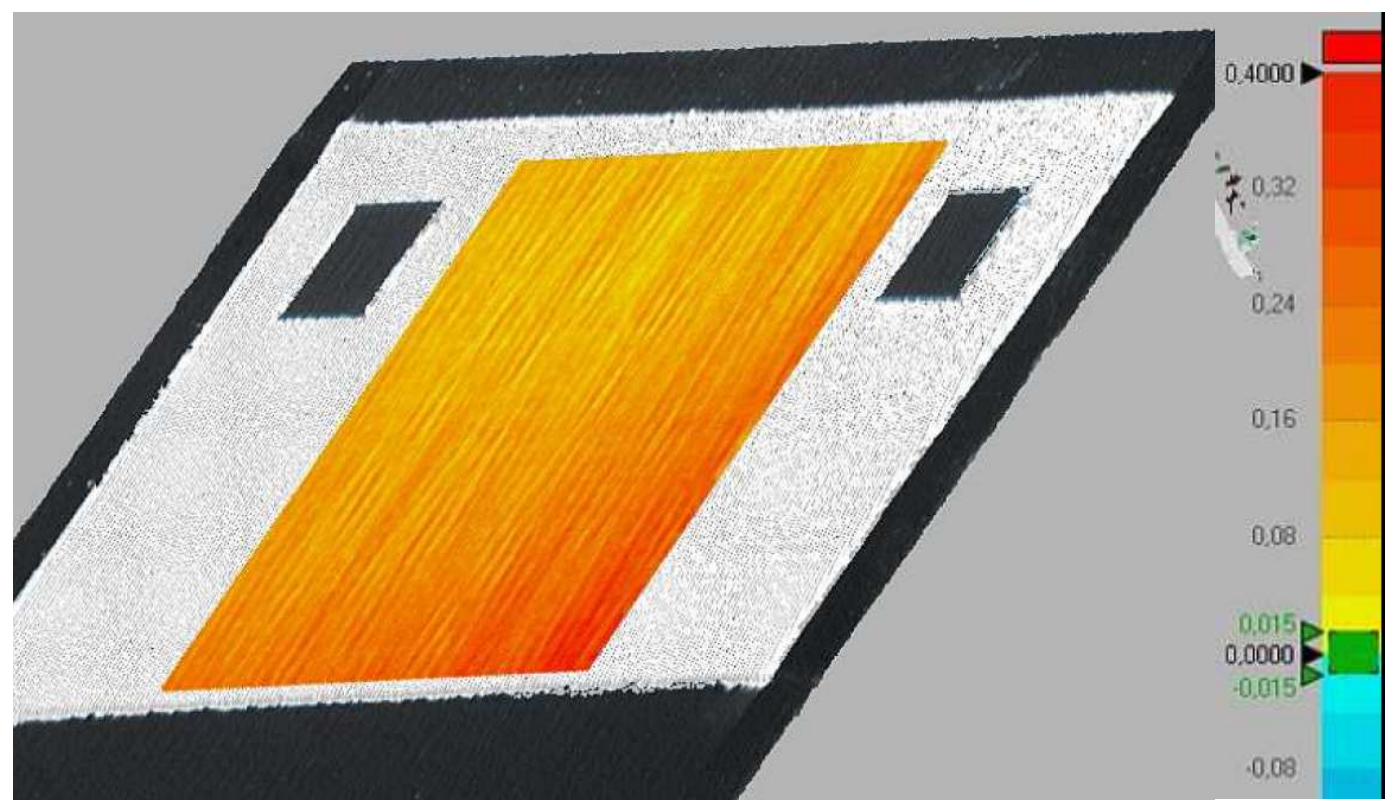

Fig. 13. Visual image example of the surface structure of the tested coating obtained by means of $3 D$ scanner

In the table 1 the results obtained for several tested samples are shown. Generally it should be emphasized that the measurement results are very sensitive to measurement conditions and the thickness of paint layer. In this table there are presented the thickness of paint layers, the temperature difference $\boldsymbol{\Delta T}$ between the paint cover and reference surface (i.e. surface without painting), term $\boldsymbol{\Delta} \boldsymbol{T} / \boldsymbol{\delta}$ responsible for the heat conduction through the layers and uncertainties of these quantities.

Table 1. Difference of temperature for selected samples for various temperature values of copper boards

\begin{tabular}{|c|c|c|c|c|c|c|c|c|c|c|c|}
\hline \multirow{3}{*}{$\begin{array}{c}\text { Symbol } \\
\text { of } \\
\text { sample }\end{array}$} & \multirow{2}{*}{\multicolumn{2}{|c|}{$\begin{array}{c}\text { Paint layer } \\
\text { thickness of IR } \\
\text { camera tested } \\
\text { area }\end{array}$}} & \multicolumn{9}{|c|}{ Temperature of copper boards } \\
\hline & & & \multicolumn{3}{|c|}{$10.0\left[{ }^{\circ} \mathrm{C}\right]$} & \multicolumn{3}{|c|}{$45.0\left[{ }^{\circ} \mathrm{C}\right]$} & \multicolumn{3}{|c|}{$55.0\left[{ }^{\circ} \mathrm{C}\right]$} \\
\hline & $\begin{array}{c}\boldsymbol{\delta} \\
{[\mathrm{mm}]}\end{array}$ & $\begin{array}{c}\boldsymbol{u}_{\boldsymbol{\delta}} \\
{[\mathrm{mm}]}\end{array}$ & $\underset{[\mathrm{K}]}{\Delta T}$ & $\begin{array}{c}u_{\Delta T} \\
{[\mathrm{~K}]}\end{array}$ & $\begin{array}{c}\Delta \boldsymbol{\Delta} / \boldsymbol{\delta} \\
{[\mathrm{K} / \mathrm{mm}]}\end{array}$ & $\underset{[\mathrm{K}]}{\Delta T}$ & $\begin{array}{c}u_{\Delta T} \\
{[\mathrm{~K}]}\end{array}$ & $\begin{array}{c}\Delta \boldsymbol{\Delta} / \boldsymbol{\delta} \\
{[\mathrm{K} / \mathrm{mm}]}\end{array}$ & $\underset{[\mathrm{K}]}{\Delta T}$ & $\begin{array}{c}u_{\Delta T} \\
{[\mathrm{~K}]}\end{array}$ & $\begin{array}{c}\boldsymbol{\Delta T} / \boldsymbol{\delta} \\
{[\mathrm{K} / \mathrm{mm}]}\end{array}$ \\
\hline $\mathbf{X 2}$ & 0.29 & 0.028 & - & - & - & 0.37 & 0.38 & 1.28 & 0.37 & 0.43 & 1.28 \\
\hline X3 & 0.33 & 0.023 & 0.75 & 0.40 & 2.27 & 0.19 & 0.31 & 0.58 & 0.48 & 0.27 & 1.45 \\
\hline $\mathbf{X 4}$ & 0.28 & 0.023 & 0.71 & 0.42 & 2.54 & 0.49 & 0.32 & 1.75 & 0.68 & 0.30 & 2.43 \\
\hline $\mathrm{X6}$ & 0.40 & 0.068 & 0.56 & 0.46 & 1.40 & 0.48 & 0.43 & 1.20 & 0.60 & 0.43 & 1.50 \\
\hline
\end{tabular}

During these tests the higher temperature values of painted surface in comparison with the temperature of reference surface were obtained than in previous experiments when the temperature of copper boards was higher than the temperature of air. It proves that these paints can be put on the inner but also outer surfaces of building external walls. Summing up, if these paints are put on the inner surfaces inside the enclosed spaces (when the surroundings temperature is lower than the temperature inside house) the amount of heat flowing through the building wall into surroundings will be diminished because the temperature of painted surfaces inside the building will be increased (see Fig. 12) and the intensity of heat exchanging between the air and wall surfaces inside will be reduced. Similarly, if these paints are put on the outer surfaces of the building walls the heat flux flowing through the building wall into surroundings 


\subsection{1/qirt.2016.067}

will be also reduced because the temperature of painted surfaces will be decreased (see Figs 6, 9) and the intensity of heat exchanging between the air and wall surfaces will be reduced as well.

\section{Final remarks}

The measurement results allowed to compare the insulation efficiency of various kinds of the tested paints. It was also possible to estimate the scale of the temperature drop inside the protection layer of considered coatings in relation with the thickness of these layers as well as the content of applied special component.

In the paper the results of testing the heat protection features of the thermal resistant paints used in building technology have been presented. The various types of paints with different contents of the special components enhancing their insulation properties were examined. Due to marketing reasons the names, symbols and compositions of the tested paints can not be specified. Because of the same reasons the presented results are mainly of qualitative character.

\section{Acknowledgements}

The scientific work was supported by Faculty of Energy and Environmental Engineering of the Silesian University of Technology within the statutory research.

\section{REFERENCES}

[1] Chwieduk D., Sun energetics of the building (in Polish), Wyd. Arkady, Warszawa, 2011.

[2] Laskowski H., Thermal protection and the energy characteristic of building (in Polish). Oficyna Wyd. Pol. Warszawskiej, Warszawa, 2005.

[3] Kruczek T., Determination of annual heat losses from heat and steam pipeline networks and economic analysis of their thermomodernisation. Energy, vol. 62, pp. 120-131, 2013.

[4] Rochatka T., A method of determining the heat flux density based on a thermovision photo (in Polish), Measurement Automation and Monitoring, vol. 57 (2011), No 10, pp. 1183-1186.

[5] Kruczek T., Use of infrared camera in energy diagnostics of the objects placed in open air space in particular at non-isothermal sky. Energy, vol. 91, pp.35-47, 2015.

[6] Minkina W., Dudzik S., Infrared Thermography - Errors and Uncertainties. Wiley \& Sons, UK; 2009.

[7] Madura H. et al., Thermovison measurements in practice (in Polish). Agenda Wyd. PAK, Warszawa, 2004. 